\title{
Persistence of effects of a brief intervention on parental restrictions of teen driving privileges
}

\author{
B G Simons-Morton, J L Hartos, K H Beck
}

Injury Prevention 2003;9:142-146

See end of article for authors' affiliations

Correspondence to:

Dr Bruce Simons-Morton Prevention Research

Branch, National Institute of Child Health and Human Development, 6100 Executive Blvd Rm 7B05, Bethesda, MD

20892-7510, USA;

mortonb@mail.nih.gov

\begin{abstract}
Objective: The purpose of this study was to determine the extent to which effects of exposure to a brief intervention designed to increase parental restrictions on teen driving privileges persisted over time. Design: A total of 658 parents and their 16 year old adolescents were recruited from a local motor vehicle administration (MVA) site as adolescents successfully tested for provisional licenses. At the MVA, parents completed written surveys about expected teen driving during the first month of provisional licensure. Afterwards, on weeks assigned as intervention, parents watched a video and were given the video and a driving agreement to take home. Both parents and teens completed follow up telephone interviews about communication, amounts, and limits on teen driving at one month (579 dyads), four months (529 dyads), and nine months (528 dyads).

Results: The results indicated that both intervention parents and teens were much more likely to report using a driving agreement at each follow up during the nine month period. Significant treatment group differences persisted for communication about driving, but effects related to limits on teen driving that were evident at one month declined over time. Reports for passenger, road, and overall limits remained significant at four months; fewer were present at nine months. There were no differences in amounts of teen driving at four or nine months.

Conclusions: It is possible to reach parents through brief interventions at the MVA and successfully promote increases in initial parental restrictions on teen driving with modest persistence for at least four months.
\end{abstract}

riving a motor vehicle is one of the most dangerous endeavors of daily life as tens of thousands of Americans die annually on roads and highways in the United States. ${ }^{1}$ Driving risks are particularly increased among young drivers, especially during the first month after licensure, ${ }^{2}$ and teen crash rates are several times greater than those for older drivers for at least the first two years of licensure. ${ }^{3}$ While some portion of risk may be attributable to risky driving behavior such as speeding and tailgating, ${ }^{4}$ much more can be attributed to the complexity of the driving task. It takes thousands of miles of independent driving to develop the proficiency and judgment associated with lower crash risks among experienced drivers. ${ }^{5}$ Unfortunately, driver licensing procedures assure only that eligible teenagers have the minimum skill level necessary for maneuvering a vehicle and a basic understanding of the rules of the road. ${ }^{67}$

Young age and inexperience with driving are inextricably associated with motor vehicle crash rates. ${ }^{48}$ However, driving risk among young drivers is particularly increased under certain driving conditions, ${ }^{9}$ including late night driving ${ }^{10}{ }^{11}$ and transporting teen passengers. ${ }^{12}{ }^{13}$ Most states have adopted graduated driver licensing (GDL) policies that require increased practice driving and restricted driving experience before teens can drive unrestricted..$^{14}$ These requirements tend to lengthen the learner's permit phase and effectively delay licensure, which has beneficial effects on crash rates. ${ }^{8}{ }^{15} \mathrm{GDL}$, a policy innovation, ${ }^{16}{ }^{17}$ has been demonstrated to be effective in reducing statewide crash rates among teens, ${ }^{18}{ }^{19}$ and is now viewed as the primary means by which young driver crash rates can be reduced. ${ }^{914} 20$

GDL, however, is largely passive and parents are the true enforcers of GDL policies and any other restrictions on teen driving because they can control access to the car. ${ }^{21-23}$ Viewed from this perspective, GDL establishes basic restrictions on young drivers and makes restriction normative, which might make it easier for parents to limit initial driving privileges, ${ }^{24}$ despite teens intense motivation to drive. ${ }^{25}$ In addition, most parents impose modest restrictions on teen driving ${ }^{23}$ and parental restrictions are negatively associated with risky driving among young drivers. ${ }^{26}$ However, in general, parents allow their teens greater driving privileges than is consistent with safety. ${ }^{26}$ For example, most parents allow teens to drive with multiple teen passengers even though this is related to teen injury and death. Thus, parents in a GDL state might be receptive to persuasive messages about managing teen driving, particularly if an effective and manageable solution were made available to them at that time. ${ }^{27}$

Because most teens are accompanied by a parent at a motor vehicle administration (MVA) office when testing for provisional licenses, we exposed parents and teens to persuasive communications about parental management of teen driving at that time. A previous report indicated evidence of short term effects on parental restrictions among parents exposed to the brief intervention delivered at the MVA..$^{28}$ The purpose of this report is to describe the persistence of treatment group effects on parental management of teen driving at four and nine months post-licensure.

\section{METHODS}

\section{Participants}

Of the 756 eligible parent-adolescent dyads that were approached for this study, 658 dyads $(87 \%)$ agreed to take part. Demographic data at baseline indicated that of the participating parents, $97 \%$ were the adolescents' biological parents ( $60 \%$ mothers), $83 \%$ were white, $88 \%$ were married, $69 \%$ worked full time, $76 \%$ had a four year college education or

Abbreviations: GDL, graduated driver licensing; MVA, motor vehicle administration 
higher, and $85 \%$ had an annual household income of over $\$ 70$ 000. (The median household income for the Maryland suburban area that the MVA site serves as $\$ 76421.00 .^{29}$ ) Of the adolescents, $50 \%$ were female, $81 \%$ were white, $61 \%$ were under 16 years 6 months, and $64 \%$ were in 10th grade.

Of the recruited families, $88 \%$ (579 out of $658 ; 283$ intervention and 296 control) of parent-teen dyads completed follow up interviews at one month, 529 dyads (253 intervention; 276 control) at four months, and 528 dyads (249 intervention; 279 control) at nine months. Of all the demographic characteristics only teen gender differed significantly by group assignment at the nine month interview (females were $46 \%$ of the intervention group and $56 \%$ of the control group).

\section{Procedures}

Investigators received permission to recruit at a local MVA site in Maryland. Recruitment took place from June 2001 to November 2001. Trained research assistants recruited on weekday afternoons and Saturdays during the summer and on Thursdays and Saturdays during the school year.

Teens who successfully tested for a provisional license and one accompanying parent were asked to participate in the Checkpoints Program to "check up" on Maryland's teens during the first year of provisional licensure. As teens completed paperwork for the MVA, parents completed brief written surveys in a separate part of the MVA designated for this study. Parents and teens completed 20 minute follow up interviews at one, four, and nine months of provisional licensure. Parental consent and adolescent assent were obtained according to procedures approved by the Institutional Review Boards of the National Institute of Child Health and Human Development and the University of Maryland.

\section{Checkpoints intervention}

Each week of recruitment was designated as intervention or control. On intervention weeks, after completing baseline surveys, parents watched the Checkpoints video (nine minutes) that presents the risks of teen driving, the Checkpoints program, and families who used and liked the program. Afterwards, parents were given a copy of the video and the Checkpoints Parent-Teen Driving Agreement, which includes information about teen driving risks, advantages of completing the agreement, and sections for families to set rules, consequences, and driving limits on teen driving with teen passengers, at night, and on high speed roads. Families were encouraged to adopt initial limits that are strict and to relax them over time as teens gain more driving experience and show responsible behavior. One week after recruitment, intervention families were sent a follow up newsletter addressed to both parent and teen that summarized ways parents could manage their teens' early driving and encouraged use of the Checkpoints Driving Agreement.

\section{Measures}

All measures were adapted from our program of research on young drivers. ${ }^{21}$ Outcome variables addressed communication, amount, and limits related to teen driving and were obtained from follow up interviews at one, four, and nine months. Driving discussion was assessed by parent and teen reports on two items (parent alpha $=0.77$; teen alpha $=0.69$ ) assessing how often (four point scale: "never", "a few times", "more than a few times", "many times") parents talked to teens about driving rules and consequences for violations during the one month period before the interview. Driving consequences were assessed by parent and teen reports for whether parents would reduce driving privileges ( 10 point scale: "definitely no" to "definitely yes") if teens did any of 13 irresponsible behaviors related to driving (parent alpha $=0.91$; teen alpha $=0.90$ ) Sample items include "drink and drive" and "drive aggressively".
Vehicle access was assessed by parent reports of how often (seven point scale: "less than once a week" to "more than once a day") teens had access to a vehicle during the month prior to the interview. Restricted driving was assessed by parent reports of how often ( 10 point scale: "frequently" to "never") teens were allowed to drive under 13 high risk driving conditions (parent alpha $=0.79$ ) in the month before the interview. Sample items include "with two or more friends as passengers" and "outside of local or familiar areas".Past month was assessed by teen reports of the number of days (0-30) that they drove in the past 30 days. High risk driving was assessed by teen reports of the number of days (0-30) in the past 30 days that they drove under 13 high risk conditions ( alpha $=0.82$ ). Sample items include "on high speed roads" and "between 10 pm and midnight". In addition, the numbers of traffic tickets and motor vehicle crashes were assessed by teen reports at months 4 and 9 .

Limits on teen passengers were assessed by asking how many teen passengers (five point scale: "no limits", "three teens", "two teens", "one teen", "no teens") were allowed when the teen drove. Limits on high speed roads were assessed by asking the types of roads (five point scale: "no limits", "all but a few risky roads", "most but no highways", "local roads only", "neighborhood roads only") teens were allowed to drive. Weekday night restriction and weekend night restrictions were assessed by asking how late (five point scale: "after 11 pm", "by 11 pm", "by 10 pm", "by 9 pm", "by 8 pm") teens were allowed to drive on weekend nights. Use of a driving agreement was assessed by asking parents and teens whether ("yes" or "no") they are using a parent-teen driving agreement.

Parents reported teen gender, race/ethnicity, age, and grade; parent gender, race/ethnicity, age, marital status, educational level, and work status; and family income at baseline. Parents also reported expected driving limits at that time by responding to how often ( 10 point scale: "frequently" to "never") adolescents would be allowed to drive under 13 conditions (alpha $=$ 0.81 ). Items included "without getting permission" and "between 10 pm and midnight".

\section{Analysis}

Treatment group differences were assessed for all outcome variables, and separate analyses were conducted for parent and teen reports. Odds ratios were used to compare the prevalence of driving agreement use by group. Between-group $t$ tests were conducted to determine group differences for outcome variables addressing communication, amount, and limits related to teen driving. Scale scores for driving discussion, driving consequences, restricted driving, high risk driving, and expected driving limits were derived by summing the scores for the items in the scale and dividing by the total number of items. In addition, separate composite scores of driving limits were derived by adding the scores for teen passenger limits, high speed road limits, weekday night driving restriction, and weekend night driving restriction. Higher scores reflect stricter limits. A repeated measures analysis of variance was conducted to assess significant differences in composite driving limits across time and when taking parent and teen gender and baseline expectations for teen driving limits into consideration.

\section{RESULTS}

As shown in table 1, group differences emerged for reports of driving agreement use. Intervention parents and teens were more likely to report using a driving agreement at each time point: about 3 and 5 times, respectively, at one month; about 4.8 and almost 6.5 times, respectively, at four months; and about 3 and 4.8 times, respectively, nine months.

Table 2 shows the unadjusted treatment group differences for outcome variables related to communication about teen driving, amount of teen driving, and limits on teen driving. 
Table 1 Percent of parents and teens reporting use of a driving agreement and odds ratios and $95 \%$ confidence intervals for differences

\begin{tabular}{|c|c|c|c|c|c|c|c|c|}
\hline \multirow[b]{2}{*}{ Time } & \multicolumn{2}{|c|}{ No $(\%)$ of parents } & \multirow[b]{2}{*}{$\begin{array}{l}\text { Odds } \\
\text { ratio }\end{array}$} & \multirow[b]{2}{*}{$\begin{array}{l}95 \% \text { Confidence } \\
\text { intervals }\end{array}$} & \multicolumn{2}{|c|}{ No (\%) of teens } & \multirow[b]{2}{*}{$\begin{array}{l}\text { Odds } \\
\text { ratio }\end{array}$} & \multirow[b]{2}{*}{$\begin{array}{l}95 \% \text { Confidence } \\
\text { intervals }\end{array}$} \\
\hline & $\begin{array}{l}\text { Intervention } \\
\text { group }\end{array}$ & Control group & & & $\begin{array}{l}\text { Intervention } \\
\text { group }\end{array}$ & Control group & & \\
\hline Month 1 & $283(62)$ & $296(38)$ & 3.14 & 2.23 to 4.41 & $283(65)$ & $296(35)$ & 4.98 & 3.48 to 7.13 \\
\hline Month 4 & 253 (65) & $276(35)$ & 4.79 & 3.31 to 6.94 & 253 (69) & $276(31)$ & 6.46 & 4.42 to 9.44 \\
\hline Month 9 & 249 (61) & 279 (39) & 3.04 & 2.13 to 4.34 & 249 (69) & $279(31)$ & 4.78 & 3.29 to 6.94 \\
\hline
\end{tabular}

Table 2 Treatment group differences: means, SDs, and $t$ test results

\begin{tabular}{|c|c|c|c|c|c|c|c|c|c|c|c|c|c|c|c|c|}
\hline \multirow[b]{3}{*}{ Variables } & \multirow[b]{3}{*}{ Reporte } & \multicolumn{5}{|c|}{ Month 1 reports } & \multicolumn{5}{|c|}{ Month 4 reports } & \multicolumn{5}{|c|}{ Month 9 reports } \\
\hline & & \multicolumn{2}{|c|}{$\begin{array}{l}\text { Intervention } \\
\text { group } \\
\text { ( } n=283 \\
\text { dyads) }\end{array}$} & \multicolumn{2}{|c|}{$\begin{array}{l}\text { Control } \\
\text { group } \\
\text { (n=296 } \\
\text { dyads) }\end{array}$} & \multirow[b]{2}{*}{$t$} & \multicolumn{2}{|c|}{$\begin{array}{l}\text { Intervention } \\
\text { group } \\
\text { ( } n=253 \\
\text { dyads) }\end{array}$} & \multicolumn{2}{|c|}{$\begin{array}{l}\text { Control } \\
\text { group } \\
\text { ( } n=276 \\
\text { dyads) }\end{array}$} & \multirow[b]{2}{*}{$t$} & \multicolumn{2}{|c|}{$\begin{array}{l}\text { Intervention } \\
\text { group } \\
\text { ( } n=249 \\
\text { dyads) }\end{array}$} & \multicolumn{2}{|c|}{$\begin{array}{l}\text { Control } \\
\text { group } \\
\text { ( } n=279 \\
\text { dyads) }\end{array}$} & \multirow[b]{2}{*}{$t$} \\
\hline & & r Mean & SD & Mean & SD & & Mean & SD & Mean & SD & & Mean & SD & Mean & SD & \\
\hline \multicolumn{17}{|l|}{$\begin{array}{l}\text { Communication about teen } \\
\text { driving }\end{array}$} \\
\hline \multirow[t]{2}{*}{ Driving discussion } & Parent & 3.20 & 0.87 & 3.20 & 0.88 & NS & 2.76 & 0.96 & 2.52 & 0.94 & $2.90 * *$ & 2.35 & 0.90 & 2.17 & 0.58 & $2.35^{*}$ \\
\hline & Teen & 2.89 & 0.93 & 2.73 & 0.90 & $2.10^{*}$ & 2.37 & 1.02 & 2.18 & 0.99 & $2.14^{*}$ & 1.95 & 0.82 & 1.80 & 0.79 & $2.14^{*}$ \\
\hline \multirow[t]{2}{*}{ Driving consequences } & Parent & 9.20 & 1.22 & 8.96 & 1.49 & $2.00 *$ & 8.67 & 1.39 & 8.35 & 1.60 & $2.45^{*}$ & 8.31 & 1.49 & 7.99 & 1.65 & 2.29 * \\
\hline & Teen & 8.26 & 1.68 & 7.94 & 1.58 & $2.35^{*}$ & 7.49 & 1.65 & 6.87 & 1.65 & 4.36 *** & * 6.93 & 1.75 & 6.59 & 1.76 & 2.22 * \\
\hline \multicolumn{17}{|l|}{ Amount of teen driving } \\
\hline Vehicle access & Parent & 4.42 & 1.63 & 4.71 & 1.57 & $-2.18^{*}$ & 5.25 & 1.67 & 5.14 & 1.60 & NS & 5.48 & 1.56 & 5.62 & 1.48 & NS \\
\hline Restricted driving & Parent & 8.62 & 1.06 & 8.22 & 1.15 & 4.28 *** & * 7.63 & 1.22 & 7.47 & 1.30 & NS & 6.96 & 1.28 & 6.79 & 1.30 & NS \\
\hline Past month driving & Teen & 19.15 & 58.64 & 19.38 & 8.34 & NS & 21.95 & 7.55 & 22.46 & 7.26 & NS & 22.72 & 27.21 & 23.32 & 7.34 & NS \\
\hline High risk driving & Teen & 3.58 & 3.02 & 4.11 & 3.03 & $-2.11^{*}$ & 5.52 & 3.45 & 5.65 & 3.21 & NS & 6.40 & 3.76 & 6.60 & 3.58 & NS \\
\hline Tickets & Teen & - & & - & & - & 0.09 & 0.32 & 0.06 & 0.23 & NS & 0.14 & 0.36 & 0.15 & 0.38 & NS \\
\hline \multirow{2}{*}{\multicolumn{17}{|c|}{ Limits on teen driving }} \\
\hline & & & & & & & & & & & & & & & & \\
\hline \multirow[t]{2}{*}{ Teen passengers } & Parent & 3.4 & 0.89 & 2.84 & 0.97 & $2.55^{*}$ & 2.32 & 1.01 & 2.21 & 1.10 & NS & 1.93 & 0.93 & 1.79 & 1.04 & NS \\
\hline & Teen & 2.81 & 1.14 & 2.35 & 1.25 & 4.53 *** & * 1.84 & 1.16 & 1.58 & 1.21 & $2.50^{*}$ & 1.27 & 1.08 & 1.13 & 1.08 & NS \\
\hline \multirow[t]{2}{*}{ High speed roads } & Parent & 2.35 & 1.12 & 1.99 & 1.27 & $3.62 * * *$ & * 1.85 & 1.14 & 1.55 & 1.13 & 3.06 ** & 1.37 & 1.08 & 1.21 & 1.12 & NS \\
\hline & Teen & 1.71 & 1.17 & 1.38 & 1.20 & $3.43 * *$ & 1.15 & 1.00 & 0.96 & 0.96 & $2.27^{*}$ & 0.69 & 0.83 & 0.66 & 0.84 & NS \\
\hline \multirow{2}{*}{ Weekday night restriction } & Parent & 2.21 & 1.37 & 1.91 & 1.45 & $2.52^{*}$ & 1.93 & 1.31 & 1.85 & 1.37 & NS & 1.43 & 1.28 & 1.34 & 1.25 & NS \\
\hline & Teen & 1.96 & 1.51 & 1.39 & 1.45 & $4.63^{* * *}$ & * 1.64 & 1.31 & 1.44 & 1.29 & NS & 1.08 & 1.22 & 1.05 & 1.16 & NS \\
\hline \multirow[t]{2}{*}{ Weekend night restriction } & Parent & 1.65 & 1.43 & 1.21 & 1.41 & 3.72 *** & * 0.57 & 0.89 & 0.47 & 0.94 & NS & 0.45 & 0.98 & 0.28 & 0.77 & $2.17^{*}$ \\
\hline & Teen & 1.46 & 1.54 & 0.81 & 1.20 & $5.64 * * *$ & * 0.44 & 0.86 & 0.47 & 0.94 & NS & 0.26 & 0.73 & 0.24 & 0.69 & NS \\
\hline \multirow[t]{2}{*}{ Driving limits } & Parent & 9.24 & 3.19 & 7.94 & 3.57 & 4.59 *** & * 6.67 & 2.84 & 6.08 & 3.01 & $2.34^{*}$ & 5.17 & 2.83 & 4.62 & 2.78 & 2.51 * \\
\hline & Teen & 7.94 & 4.04 & 5.93 & 3.42 & $6.45^{* * *}$ & * 5.07 & 2.95 & 4.37 & 2.71 & $2.82^{* *}$ & 3.29 & 2.57 & 3.09 & 2.59 & NS \\
\hline
\end{tabular}

With respect to parent-teen communication about driving, results of $t$ tests indicated group differences in driving discussion and driving consequences at month 1 , month 4 , and month 9. At month 1, both intervention parents and teens were significantly more likely to report that parents would take away driving privileges if teens performed unsafe driving than did those in the control group. In addition, intervention teens reported more discussion of driving than did those in the control group. At months 4 and 9, intervention parents and teens reported more driving discussion and consequences than did control parents and teens.

Also shown in table 2 are significant treatment group differences for outcome variables related to amounts of teen driving. At one month, intervention group parents reported less vehicle access and more restricted driving than did those in the control group. Although teen reports did not differ for the number of days in which they drove within the past 30 days, intervention group teens reported less driving under high risk conditions during that time period than did controlgroup teens. However, these group differences were not evident at months 4 and 9. There were also no group differences in number of tickets or crashes teens reported at months 4 and 9. Although the numbers increased over time, most teens stayed violation free $(91 \%$ of intervention and $94 \%$ control at month $4 ; 87 \%$ of intervention and $86 \%$ control at month 9) and accident free (83\% intervention and $80 \%$ control at month 4; 65\% intervention and 69\% control at month 9).

With respect to outcome variables related to limits on teen driving, all teen and parent measures differed by treatment group at month 1 , including limits for teen passengers, high speed roads, driving night restrictions, and overall amounts of limits. However, as noted in table 2 , and shown in figs $1-5$, the differences declined over time. At month 4, intervention parents and teens reported more overall driving limits, intervention parents and teens reported more limits on high speed roads, and intervention teens reported stricter passenger limits than did those in the control group. By month 9, only parent reported weekend and overall driving limits differed by group.

To confirm an overall treatment effect on composite scores for driving limits across time, a repeated measures multivariate analysis of variance was conducted. This procedure allows the use of the same dependent variable at multiple time points as multiple dependent variables, and the inclusion of control variables or covariates that adjust the resulting linear combination to reflect their influence. Thus, a repeated measures multivariate analysis of variance regressed reporter (parent or teen) and time (composite driving limits at one, four, and nine months) on group (intervention or control) while controlling 


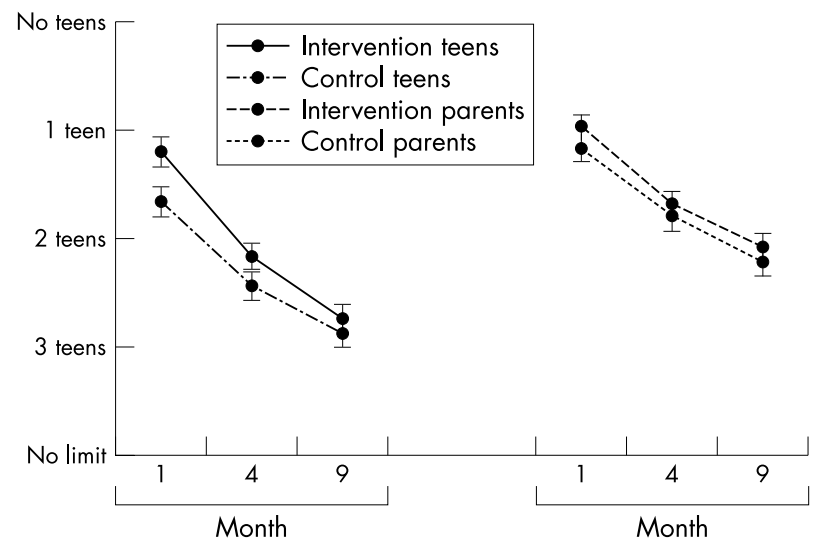

Figure 1 Parent and teen reported driving limits for teen passengers: means and $95 \%$ confidence intervals.

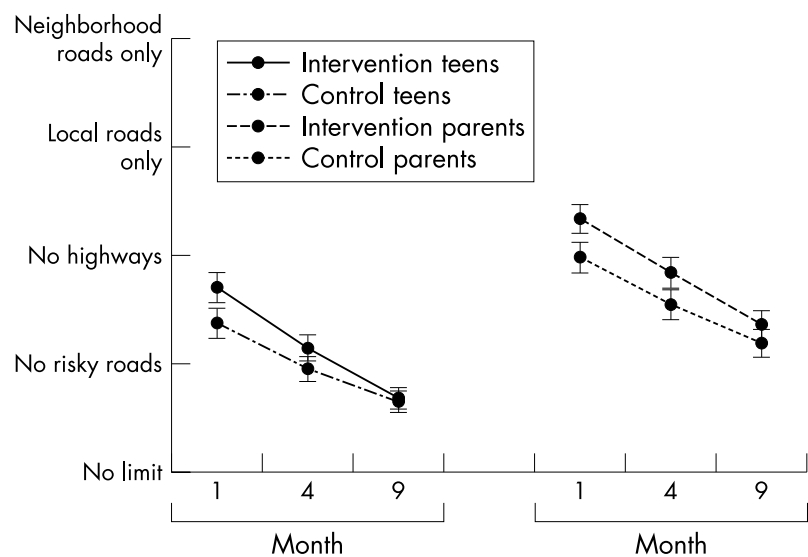

Figure 2 Parent and teen reported driving limits for high speed roads: means and $95 \%$ confidence intervals.

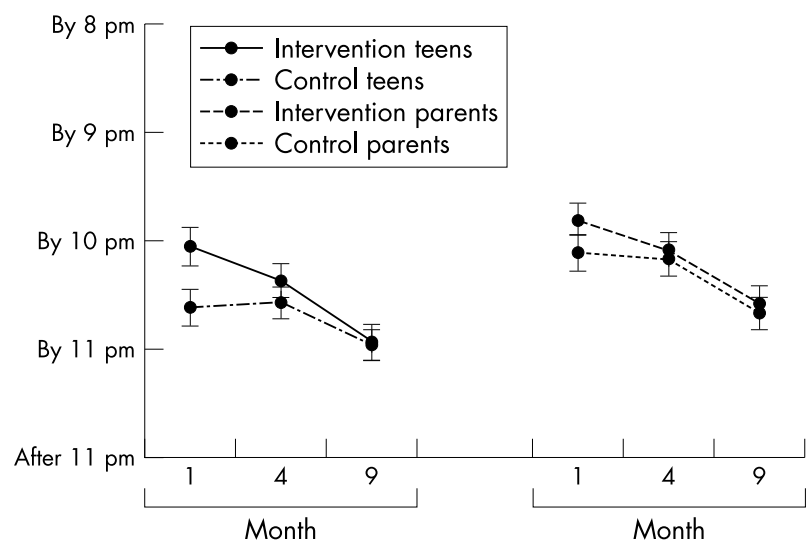

Figure 3 Parent and teen reported weekday night driving restrictions: means and $95 \%$ confidence intervals.

for parent and teen genders and expected driving limits. The results yielded a significant three way interaction effect $(\mathrm{F}=$ 4.62, $\mathrm{df}=2,435, \mathrm{p}>0.01$ ) for reporter $X$ driving limits $X$ group. This confirms that group differences in driving limits exist when all time points are considered together and when controlling for parent and teen gender and expected driving limits from baseline. There were no significant three way interactions for any other combination of variables.

\section{DISCUSSION}

Significant treatment group effects at one month for the brief intervention described in the present paper on parent

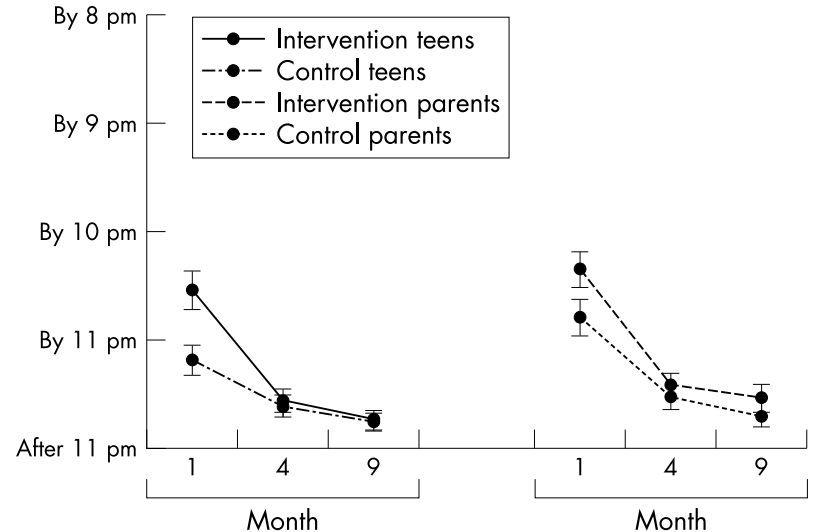

Figure 4 Parent and teen reported weekend night driving restrictions: means and $95 \%$ confidence intervals.

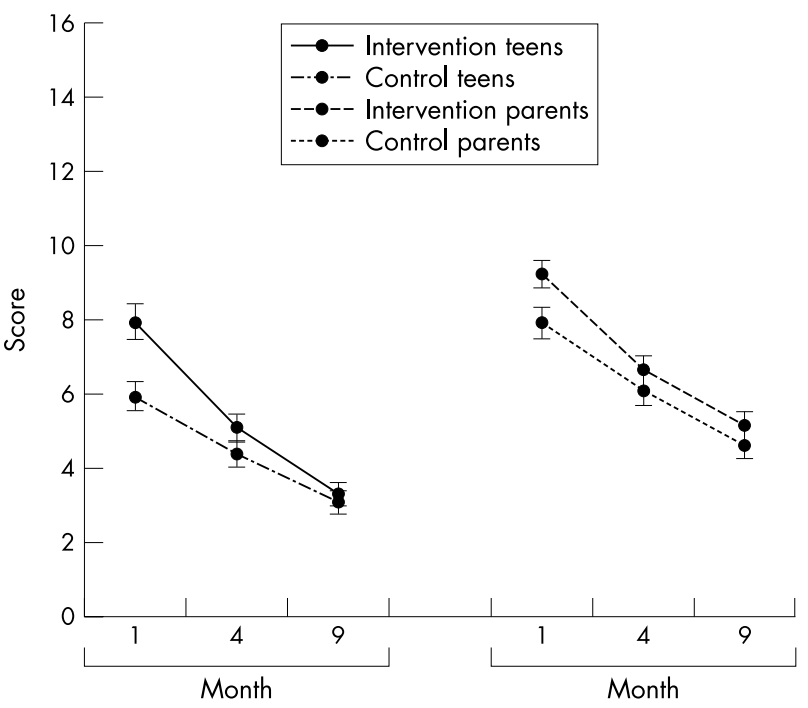

Figure 5 Parent and teen composite scores for driving limits: means and $95 \%$ confidence intervals.

management of teen driving were reported in a previous report. ${ }^{28}$ The present report examines the persistence of these effects at four and nine month follow up assessments. The present research is the first to demonstrate that exposure at the time of teen provisional licensure to a brief intervention consisting of a persuasive video, a parent-teen driving agreement, and a single follow up message can effectively increase parental restrictions on teen driving privileges.

The results of this study indicated that significant treatment group differences in reports of restrictions on teen passengers, high speed roads, and overall limits were maintained through four months. Even though treatment group differences were modest in size and effects generally decayed over time, treatment group differences on parent reported weekend night restriction and overall restrictions remained significant at the nine month interview. In addition, intervention group restrictions were consistent with the Checkpoints Program recommendations that parents provide strict initial restrictions and gradually relax them over time. Moreover, the overall pattern of treatment group differences as reported by parents and teens were similar. The results also indicated that parent-teen communication about teen driving was enhanced for the entire nine month period.

The study has a number of strengths. By conducting the study at an MVA office, there was assurance that $100 \%$ of those randomized to the intervention group watched the video and received the Checkpoints Parent-Teen Driving Agreement. In 


\section{Key points}

- The extremely high crash risk during the first six months of independent driving can be reduced by restricting driving to lower risk conditions while teens gain driving experience.

- Previous research has been shown that it is possible to significantly increase parental restrictions during the first several months of independent driving.

- In this randomized trial effects on the adoption of a parentteen driving agreement and limits on teen driving privileges were shown to persisted for up to nine months after provisional licensure.

- The research demonstrates the efficacy of a brief intervention administered at the time of provisional licensure.

addition, this intervention included a small, but potentially powerful dose of personal persuasion when a research assistant gave the study participants the Checkpoints materials and encouraged the family to use them. This is in contrast to another trial where parents received the Checkpoints materials by mail over time and actual exposure could only be estimated by asking study participants about their receipt and use of materials. ${ }^{21}$ In the present study, Checkpoints materials were delivered as a brief intervention at a MVA facility, without disrupting the operational functioning of this licensing agency, but in a manner that assured that families were exposed to the materials and encouraged to negotiate the parent-teen driving agreement. The results achieved are promising and provide support for the practical utility of this approach.

The study findings, however, are limited in several ways. The results may not necessarily generalize to other settings and populations because the research was conducted in only one local MVA office with a mostly white and upper socioeconomic status population. Also, Maryland was one of the first states to adopt GDL and introduced new GDL provisions in 1999. Thus, Maryland parents may be more progressive and sensitized when it comes to this issue than would be parents in states with newer and/or weaker GDL programs. Fortunately, our randomized design should have assured that any bias would have been equivalent for both intervention and control participants.

Moreover, the observed increases in parental restrictions on teen driving due to exposure to the Checkpoints Program materials may not be significant enough to impact risk among novice teen drivers. Both the magnitude of the effects and their persistence are less than ideal. For example, though significantly different through four months, on average, parents in both treatment groups allowed over one teen passenger at one month, nearly two teen passengers by the fourth month, and more than two teen passengers by nine months. Nevertheless, the observed differences are a step in the right direction and are potentially important if applied to a large population.

Notably, the present study provides a practical model for how parental management of young drivers could be encouraged broadly through licensing practices at the MVA. Indeed, should these findings be confirmed in other research, it might be possible to incorporate into general practice at MVA offices the delivery of parent-teen driving agreements and persuasive media messages about the risks of teen driving and the benefits of parental restrictions to all families.

\section{ACKNOWLEDGEMENTS}

Support from the Maryland Department of Transportation, State Highway Administration; Cooperation of the Maryland Motor Vehicle Administration.

\section{Authors' affiliations}

B G Simons-Morton, J L Hartos, Prevention Research Branch, Nationa Institute of Child Health and Human Development, Bethesda, Maryland K H Beck, Department of Public and Community Health, University of Maryland

\section{REFERENCES}

1 Centers for Disease Control and Prevention. Motor vehicle safety-a 20th century public health achievement. MMWR Morb Mortal Wkly Rep 1999;48:369-74.

2 McCartt AT, Shabanova VI, Leaf WA. Driving experience, crashes, and traffic citations of teenage beginning drivers. Accid Anal Prev (in press).

3 Ulmer RG, Williams AF, Preusser D. Crash involvements of 16-year-old drivers. J Safety Res 1997;28:97-103.

4 Williams AF, Preusser DF, Ferguson SA. Fatal crashes involving 16-year-old drivers: narrative description. J Traffic Med 1998;26:11-17.

5 Vernick JS, Li G, Ogatis S, et al. Effect of high school driver education on motor vehicle crashes, violations, and licensure. Am J Prev Med 1999; 16:40-6.

6 Mayhew DR, Simpson HM. The role of driving experience: implications for training and licensing of new drivers. Ottawa, Ontario: Traffic Injury Research Foundation, 1995.

7 Mayhew DR, Simpson HM. The safety value of driver education and training. Inj Prev 2002;8(suppl II):ii3-7.

8 Preusser DF. Delaying teenage licensure. Alcohol, Drugs and Driving 1988;4:283-95.

9 Williams AF, Ferguson SA. Rational for graduated licensing and the risks it should address. Inj Prev 2002;8(suppl II):ii9-13.

10 Doherty ST, Andrey JC, MacGregor C. The situational risks of young drivers: the influence of passengers, time of day and day of week on accident rates. Accid Anal Prev 1998;30:45-52.

11 Williams AF, Preusser DF. Night driving restrictions for youthful drivers: a literature review and commentary. J Public Health Policy 1997: 18:334-45

12 Preusser DF, Ferguson SA, Williams AF. The effect of teenage passengers on the fatal crash risk of teenage drivers. Accid Anal Prev 1998; 30:217-22.

13 Chen LH, Baker SP, Braver ER, et al. Carrying passengers as a risk factor for crashes fatal to 16- and 17-year-old drivers. JAMA 2000;283:1578-618.

14 McKnight AJ, Peck RC. Graduate driver licensing: what works? Inj Prev 2002;8(suppl II):ii32-8.

15 Ferguson SA, Leaf WA, Williams AF, et al. Differences in young driver crash involvement in states with varying licensure practices. Accid Anal Prev 1996;28:171-80.

16 Simons-Morton BG. Reducing young driver crash risk. Inj Prev 2002;8(suppl II): ii l-2

17 Simons-Morton BG, Hartos JL. How well do parents manage young driver crash risks? J Safety Res (in press).

18 Shope JT, Molnar L, Elliott MR, et al. Graduated driver licensing in Michigan: early impact on motor vehicle crashes among 16-year-old drivers. JAMA 2001;286:1593-8.

19 Foss RD, Feaganes JR, Rodgman EA. Initial effects of graduated driving licensing on 16-year-old driver crashes in North Carolina. JAMA 2001;286: 1588-92.

20 Insurance Institute for Highway Safety. Recommendations for an ideal graduated licensing law. Status Report 1999,34:6

21 Simons-Morton, BG, Hartos JL, Leaf WA. Promoting parental management of teen driving. Ini Prev 2002; 8(suppl IIl):ii24-31.

22 Beck KH, Hartos JL, Simons-Morton BG. Teen driving risk: the promise of parental influence and public policy. Health Educ Behav 2002;29:73-84.

23 Preusser DF, Williams AF, Lund AK. Parental role in teenage driving. Journal of Youth and Adolescence 1985;14:73-84.

24 McCartt AT, Leaf WA, Farmer CM, et al. Effects of Florida's graduated licensing program on the behaviors and attitudes of teenagers. J Safety Res 2001;32:119-31.

25 Arnett JJ. Developmental sources of crash risk in young drivers. Inj Prev 2002;8(suppl II):ii 17-23

26 Hartos JL, Eitel P, Simons-Morton BG. Do parent-imposed delayed licensure and restricted driving reduce risky driving behaviors among newly licensed teens? Prev Sci 2001;2:111-20.

27 Bettinghaus EP. Health promotion and the knowledge-attitude-behavior continuum. Prev Med 1986;15:475-91.

28 Simons-Morton BG, Hartos JL, Beck K. Increased parent limits on teen driving: positive effects from a brief intervention administered at the MVA. Prev Science (in press).

29 MSN Home Advisor. Compare cities. Available at: http:// homeadvisor.msn.com/PickAPlace/CompareCities.asp (accessed 25 October 2001). 